From the Dana-Farber Cancer Institute Harvard Medical School, Boston, MA; St Jude Children's Research Hospital, Memphis, TN; and the Mattel Children's Hospital/University of California, Los Angeles School of Medicine, Los Angeles, CA.

Submitted March 6, 2009; accepted June 12, 2009; published online ahead of print at www.jco.org on October 19, 2009

Supported by Grant No. U24 CA55727 from the National Cancer Institute (L.L.R.) and a research grant from the American Foundation for Suicide

Prevention (C.J.R.). St Jude Children's Research Hospital is supported by the American Lebanese-Syrian Associated Charities.

Presented in part at the 5th Annual Conference of the American Psychosocial Oncology Society, February 28-March 2, 2008, Irvine, CA.

Authors' disclosures of potential conflicts of interest and author contributions are found at the end of this article.

Corresponding author: Christopher J. Recklitis, PhD, MPH, Perini Family Survivors' Center, Dana-Farber Cancer Institute, 44 Binney St, SW330, Boston, MA 02115-6084; e-mail: christopher

recklitis@dfci.harvard.edu.

(c) 2009 by American Society of Clinical Oncology

0732-183X/10/2804-655/\$20.00

DOI: $10.1200 / J C O .2009 .22 .8635$

\title{
Suicide Ideation in Adult Survivors of Childhood Cancer: A Report From the Childhood Cancer Survivor Study
}

\author{
Christopher J. Recklitis, Lisa R. Diller, Xiaochun Li, Julie Najita, Leslie L. Robison, and Lonnie Zeltzer
}

$$
\begin{array}{llllllll}
\text { A } & \text { B } & \text { S } & \text { T } & \text { R } & \text { A } & \text { C } & \text { T }
\end{array}
$$

\section{Purpose}

To evaluate risk of suicide ideation (SI) after childhood cancer, prevalence of SI in a cohort of adult survivors of pediatric cancers was compared with prevalence in a sibling comparison group. The relationship of SI to cancer treatment and current health was examined, and the hypothesis that poor physical health is significantly associated with suicidality, after adjusting for depression, was specifically tested.

\section{Methods}

Nine thousand one hundred twenty-six adult survivors of childhood cancer and 2,968 siblings enrolled onto the Childhood Cancer Survivor Study completed a survey describing their demographics and medical and psychological functioning, including SI in the prior week.

\section{Results}

Of survivors, $7.8 \%$ reported SI compared with $4.6 \%$ of controls lodds ratio $=1.79 ; 95 \% \mathrm{Cl}, 1.4$ to 2.4). Suicidality was unrelated to age, age at diagnosis, sex, cancer therapy, recurrence, time since diagnosis, or second malignancy. SI was associated with primary CNS cancer diagnosis, depression, and poor health outcomes including chronic conditions, pain, and poor global health rating. A logistic regression analysis showed that poor current physical health was significantly associated with SI even after adjusting for cancer diagnosis and depression.

\section{Conclusion}

Adult survivors of childhood cancers are at increased risk for SI. Risk of SI is related to cancer diagnosis and post-treatment mental and physical health, even many years after completion of therapy. The association of suicidal symptoms with physical health problems is important because these may be treatable conditions for which survivors seek follow-up care and underscores the need for a multidisciplinary approach to survivor care.

\section{J Clin Oncol 28:655-661. (C) 2009 by American Society of Clinical Oncology}

\section{INTRODUCTION}

Several studies have shown that cancer patients are at increased risk for suicide compared with the general population. ${ }^{1-5}$ Scandinavian registry studies, for example, have reported standardized mortality ratios for suicide deaths in cancer patients that range from 1.55 to 2.5 for males and 1.35 to 2.9 for females, compared with the general population. ${ }^{2-4}$ These studies have focused almost exclusively on patients within 1 to 5 years of first cancer diagnosis and have not examined the risk of suicide in long-term survivors. Additionally, population-based studies have not differentiated between pediatric and adult cancers, making it difficult to know if conclusions could be generalized to survivors of pediatric malignancy.

With the development of intensive treatments, the majority of pediatric cancer patients are cured of their initial cancer, ${ }^{6}$ but many go on to have late complications of treatment that interfere with later physical, ${ }^{7-11}$ psychosocial, ${ }^{12,13}$ and neurocognitive ${ }^{14}$ development. An early study of case reports indicated that childhood cancer patients may be at risk for suicide, particularly after therapy completion. ${ }^{15}$ More recently, members of our investigator team (C.J.R. and L.R.D.) ${ }^{16,17}$ reported elevated rates of suicide ideation (SI) in adult survivors of childhood cancer seen in a survivor clinic. In one study, using multiple measures of suicidal symptoms, $12.8 \%$ of these survivors reported current SI or past suicide attempt, and suicidal symptoms were associated with survivors' physical health, even after accounting for demographic and mental health variables. Identification of a relationship between suicidality and physical health outcomes has important implications for understanding the etiology of the suicide risk and for identifying those most at risk. 
To follow-up on these previous findings from single-institution studies, data from the Childhood Cancer Survivor Study (CCSS) were analyzed to determine the prevalence of SI in adult survivors of childhood cancer compared with sibling controls and to identify correlates of SI. In addition to describing the relationship of these variables to SI, the study tested the hypothesis that survivors' physical functioning and health status are associated with increased risk for SI even after adjusting for demographic variables, treatment-related variables, and self-reported depression.

\section{METHODS}

\section{Participants}

Participants were adults enrolled onto the CCSS, a multicenter cohort study of individuals treated for childhood cancer. Participating centers are provided in the Appendix. The CCSS design and cohort have been reported in detail, ${ }^{18}$ including in a recent special issue of Journal of Clinical Oncology,${ }^{19}$ and will be only briefly summarized. Eligibility criteria for the CCSS included the following: diagnosis between January 1, 1970 and December 31, 1986 with a leukemia, CNS tumor, lymphoma, kidney cancer, neuroblastoma, soft tissue sarcoma, or malignant bone tumor; diagnosis and initial therapy at one of 25 CCSS institutions; age less than 21 years at diagnosis; and survival $\geq 5$ years from diagnosis. The protocol was approved by the appropriate institutional review boards at each participating institution.

Of 20,720 eligible participants, $85.4 \%$ were successfully contacted, and $81.2 \%$ of the contacted individuals completed a baseline survey. ${ }^{19}$ Only participants $\geq$ age 18 years were administered an item inquiring about SI. Nine thousand one hundred twenty-six participants completed this survey item, and their data were included in this analysis. Participants included 4,814 men $(52.8 \%)$ and 4,312 women (47.3\%). The four largest ethnic groups were white, non-Hispanic (87.8\%); black, non-Hispanic (4.5\%); hispanic (5.1\%); and other $(2.6 \%)$. Age of the cohort ranged from 18 to 48 years, and time since diagnosis ranged from 6 to 29 years. Cancer diagnoses were classified as follows: leukemias (29.4\%), Hodgkin's disease (18.0\%), CNS tumors (12.5\%), bone tumors $(10.9 \%)$, soft tissue sarcomas $(9.7 \%)$, non-Hodgkin's lymphomas (9.2\%), Wilms tumors (6.4\%), and neuroblastomas (3.9\%). A random sample of $50 \%$ of participating survivors was asked to identify their nearest-age living sibling. These siblings were recruited to the study as noncancer controls. Data from 2,968 siblings (1,383 men and 1,585 women) with age $\geq 18$ years who completed the survey were included in this analysis. Demographic information on participants is listed in Table 1.

\section{Measures}

The CCSS collected data on participants' cancer treatment using a standardized medical record review. Patient-reported information was assessed with a 24-page mailed CCSS baseline survey covering sociodemographic information (eg, marital status, education, income, employment in the last year), medical history, functional limitations (eg, disability status), health utilization (eg, physical examination and oncology visit and hospitalizations within the last 2 years), psychological functioning, and current health and illnesses. Copies of the survey are available from the CCSS Web site. ${ }^{20}$

SI and depression rating. The CCSS baseline survey included items from the Brief Symptom Inventory-18 (BSI-18) an 18-item psychological screening inventory designed for assessing psychological distress in medical patients. ${ }^{21}$ BSI-18 items were presented with standard instructions asking participants to report the extent to which they were "distressed or bothered" in the past week by each symptom. Participants responded on a 5-point Likert scale ranging from "not at all" to "extremely." Information on the BSI-18 items, scoring, and factorial validity in the CCSS cohort have been reported previously. ${ }^{22}$ Participants who endorsed any suicidal ideation on item 9, "thoughts of ending your life," were considered to have SI. The SI item is part of the Depression scale; however, to allow for a measure of depression excluding SI, an alternative method was used to calculate the Depression score in the study. Specifically, item 9 was treated as missing in the calculation of the BSI-18 Depression score,
Table 1. Demographics and Clinical Characteristics of Adult Survivors of Childhood Cancer and Demographics of Siblings

\begin{tabular}{|c|c|c|c|c|}
\hline \multirow[b]{2}{*}{ Variable } & \multicolumn{2}{|c|}{$\begin{array}{l}\text { Survivors } \\
(n=9,126)\end{array}$} & \multicolumn{2}{|c|}{$\begin{array}{c}\text { Siblings } \\
(\mathrm{n}=2,986)\end{array}$} \\
\hline & No. & $\%$ & No. & $\%$ \\
\hline Age at interview, years & 9,126 & & 2,968 & \\
\hline $18-24$ & 3,566 & 39.1 & 861 & 29.0 \\
\hline $25-29$ & 2,501 & 27.4 & 696 & 23.5 \\
\hline $30-34$ & 1,859 & 20.4 & 647 & 21.8 \\
\hline$\geq 35$ & 1,200 & 13.2 & 764 & 25.7 \\
\hline Sex & 9,126 & & 2,968 & \\
\hline Female & 4,312 & 47.3 & 1,585 & 53.4 \\
\hline Male & 1,383 & 46.6 & 4,814 & 52.8 \\
\hline Race/ethnicity & 9,101 & & 2,869 & \\
\hline White, $\mathrm{NH}$ & 7,993 & 87.8 & 2,463 & 92.1 \\
\hline Black, NH & 408 & 4.5 & 71 & 2.5 \\
\hline Hispanic & 467 & 5.1 & 96 & 3.4 \\
\hline Other & 233 & 2.6 & 59 & 2.1 \\
\hline Education & 8,645 & & 2,843 & \\
\hline$<12$ years (some high school) & 784 & 9.1 & 157 & 5.5 \\
\hline Completed high school & 1,882 & 21.8 & 517 & 18.2 \\
\hline High school + some college* & 3,213 & 37.2 & 1,041 & 36.6 \\
\hline College/postgraduatet & 2,766 & 32.0 & 1,128 & 39.7 \\
\hline Household income & 8,039 & & 2,701 & \\
\hline$<\$ 9,999$ & 706 & 8.8 & 125 & 4.6 \\
\hline$\$ 10,000-\$ 19,000$ & 1,080 & 13.4 & 224 & 8.3 \\
\hline$\$ 20,000-\$ 39,999$ & 2,440 & 30.4 & 666 & 24.7 \\
\hline$\$ 40,000-\$ 59,999$ & 1,787 & 22.2 & 666 & 24.7 \\
\hline$>\$ 60,000$ & 2,026 & 25.2 & 1,020 & 37.8 \\
\hline Cancer diagnosis & 9,126 & & & \\
\hline Leukemia & 2,681 & 29.4 & & \\
\hline Hodgkin's disease & 1,645 & 18.0 & & \\
\hline CNS & 1,136 & 12.5 & & \\
\hline Bone & 997 & 10.9 & & \\
\hline Sarcoma & 881 & 9.7 & & \\
\hline $\mathrm{NHL}$ & 842 & 9.2 & & \\
\hline Wilms tumor & 584 & 6.4 & & \\
\hline Neuroblastoma & 360 & 3.9 & & \\
\hline Cancer treatment & 7,903 & & & \\
\hline Surgery only & 578 & 7.3 & & \\
\hline RT only & 23 & 0.3 & & \\
\hline Chemo only & 307 & 3.9 & & \\
\hline Chemo + RT & 910 & 11.5 & & \\
\hline Chemo + surgery & 1,310 & 16.6 & & \\
\hline $\mathrm{RT}+$ surgery & 1,143 & 14.5 & & \\
\hline Chemo + RT + surgery & 3,632 & 46.0 & & \\
\hline Age at cancer diagnosis, years & 9,126 & & & \\
\hline$<3$ & 820 & 9.0 & & \\
\hline $3-6$ & 2,043 & 22.4 & & \\
\hline $7-10$ & 1,764 & 19.3 & & \\
\hline $11-17$ & 3,509 & 38.5 & & \\
\hline$\geq 18$ & 990 & 10.9 & & \\
\hline Time since cancer diagnosis, years & 9,126 & & & \\
\hline 6-10 & 662 & 7.3 & & \\
\hline $11-15$ & 2,633 & 28.9 & & \\
\hline $16-20$ & 3,267 & 35.8 & & \\
\hline$\geq 21$ & 2,564 & 28.1 & & \\
\hline
\end{tabular}

NOTE. Results are adjusted for age and sex. Percentages are based on the total No. of patients with available data for each variable.

Abbreviations: NH, non-Hispanic; NHL, Non-Hodgkin's lymphoma; RT, radiation therapy; Chemo, chemotherapy.

"High school + some college $=$ high school graduate with either some college courses or other training.

tCollege/postgraduate $=$ college graduate with or without postgraduate training 
Table 2. Cancer Treatment and SI in Survivors of Childhood Cancer

\begin{tabular}{|c|c|c|c|c|c|}
\hline \multirow[b]{2}{*}{ Variable } & \multirow{2}{*}{$\begin{array}{l}\text { Total No. of } \\
\text { Survivors } \\
(N=9,126)\end{array}$} & \multicolumn{2}{|c|}{$\begin{array}{c}\text { SI in } \\
\text { Survivors }\end{array}$} & \multirow[b]{2}{*}{ OR } & \multirow[b]{2}{*}{$95 \% \mathrm{Cl}$} \\
\hline & & No. & $\%$ & & \\
\hline Diagnosis & 9,126 & & & & \\
\hline Leukemia & 2,681 & 200 & 7.5 & 1.0 & Reference \\
\hline Hodgkin's disease & 1,645 & 131 & 8.0 & 1.2 & 0.9 to 1.5 \\
\hline CNS & 1,136 & 120 & 10.6 & $1.5^{*}$ & 1.2 to 1.9 \\
\hline Bone & 997 & 76 & 7.6 & 1.1 & 0.8 to 1.4 \\
\hline Sarcoma & 881 & 64 & 7.3 & 1.0 & 0.8 to 1.4 \\
\hline NHL & 842 & 56 & 6.7 & 0.9 & 0.7 to 1.3 \\
\hline Wilms tumor & 584 & 40 & 6.9 & 0.9 & 0.6 to 1.3 \\
\hline Neuroblastoma & 360 & 26 & 7.2 & 0.9 & 0.6 to 1.4 \\
\hline Time since diagnosis, years & 9,126 & & & & \\
\hline $6-10$ & 662 & 54 & 8.2 & 1.0 & Reference \\
\hline $11-15$ & 2,633 & 207 & 7.9 & 1.0 & 0.7 to 1.3 \\
\hline $16-20$ & 3,267 & 255 & 7.8 & 1.0 & 0.7 to 1.3 \\
\hline$\geq 21$ & 2,564 & 197 & 7.7 & 1.0 & 0.7 to 1.4 \\
\hline Age at diagnosis, years & 9,126 & & & & \\
\hline$\geq 18$ & 990 & 59 & 6.0 & 1.0 & Reference \\
\hline $11-17$ & 3,509 & 283 & 8.1 & 1.4 & 1.0 to 1.8 \\
\hline $7-10$ & 1,764 & 151 & 8.6 & 1.4 & 1.0 to 2.0 \\
\hline $3-6$ & 2,043 & 154 & 7.5 & 1.2 & 0.8 to 1.8 \\
\hline$<3$ & 820 & 66 & 8.1 & 1.3 & 0.9 to 2.0 \\
\hline Cancer treatment & 7,903 & & & & \\
\hline Chemo only & 307 & 20 & 6.5 & 1.0 & Reference \\
\hline RT only & 23 & 0 & 0.0 & - & - \\
\hline Chemo + RT & 910 & 75 & 8.2 & 1.3 & 0.8 to 2.2 \\
\hline Chemo + surgery & 1,310 & 105 & 8.0 & 1.3 & 0.8 to 2.1 \\
\hline Chemo + surgery + RT & 3,632 & 309 & 8.5 & 1.4 & 0.9 to 2.2 \\
\hline Surgery only & 578 & 54 & 9.3 & 1.6 & 0.9 to 2.7 \\
\hline Surgery + RT & 1,143 & 94 & 8.2 & 1.4 & 0.8 to 2.3 \\
\hline RT & 7,921 & & & & \\
\hline None & 2,198 & 179 & 8.1 & 1.0 & Reference \\
\hline Abdomen/Pelvis & 618 & 48 & 7.8 & 0.9 & 0.7 to 1.3 \\
\hline Chest & 193 & 12 & 6.2 & 0.8 & 0.4 to 1.4 \\
\hline Head/brain & 1,829 & 170 & 9.3 & 1.1 & 0.9 to 1.4 \\
\hline Other & 3,083 & 248 & 8.0 & 1.0 & 0.8 to 1.2 \\
\hline Chemo & 7,926 & & & & \\
\hline None & 1,749 & 148 & 8.5 & 1.0 & Reference \\
\hline Alkylators & 1,786 & 159 & 8.9 & 1.0 & 0.8 to 1.3 \\
\hline Alkylators + anthracyclines & 2,467 & 209 & 8.5 & 1.0 & 0.8 to 1.2 \\
\hline Anthracyclines & 555 & 44 & 7.9 & 0.9 & 0.6 to 1.3 \\
\hline Other & 1,369 & 99 & 7.2 & 0.8 & 0.6 to 1.0 \\
\hline Surgery & 7,918 & & & & \\
\hline No & 1,244 & 95 & 7.6 & 1.0 & Reference \\
\hline Yes & 6,674 & 564 & 8.5 & 1.2 & 0.9 to 1.5 \\
\hline Recurrences & 9,126 & & & & \\
\hline No & 8,214 & 634 & 7.7 & 1.0 & Reference \\
\hline Yes & 912 & 79 & 8.7 & 1.1 & 0.9 to 1.5 \\
\hline SMN & 9,126 & & & & \\
\hline No & 8,834 & 690 & 7.8 & 1.0 & Reference \\
\hline Yes & 292 & 23 & 7.9 & 1.0 & 0.7 to 1.6 \\
\hline
\end{tabular}

NOTE. Percentages are based on the total with available data for each variable. ORs are adjusted for age and sex.

Abbreviations: SI, suicidal ideation; OR, odds ratio; NHL, Non-Hodgkin's lymphoma; Chemo, chemotherapy; RT, radiation therapy; SMN, second malignant neoplasm.

*OR differs significantly from 1.0

and the scale was scored using the published missing data rules. ${ }^{21}$ Individuals with Depression scores at or above the recommended 90th percentile (T-scores $\geq 63)^{21,23}$ were considered to have clinically significant depression symptoms.
Current medical conditions. Using participants' responses to the CCSS baseline survey, the number and severity of participants' conditions were quantified using a coding system based on the National Cancer Institute Common Terminology Criteria for Adverse Events (version 3), a scoring system developed to rate chronic and acute conditions associated with cancer therapies. The Common Terminology Criteria for Adverse Events were previously applied to the CCSS data, and details of the coding system are available in that report. ${ }^{24}$ For the study reported here, each participant was rated on the number and severity of their medical conditions by grade as follows: grade $1=$ mild, grade $2=$ moderate, grade $3=$ severe, or grade $4=$ life threatening or disabling.

\section{Statistical Analyses}

Prevalence of SI in survivors and siblings was compared using generalized estimating equations to account for family relationship and was adjusted for age and sex. The associations of SI with demographic, cancer diagnosis and treatment, and health outcome variables were evaluated individually using logistic analyses adjusting for age and sex. Responses of "Unsure" on participant-reported variables were treated as missing. Odds ratios (ORs) and 95\% CIs were determined separately for survivors and controls.

To test the hypothesis that survivors' health and physical functioning are associated with SI, hierarchical logistic regression was used with independent variables organized in conceptual blocks. Block 1 included the demographic variables of age and sex because these have previously been reported to be suicide correlates. ${ }^{25}$ Male sex and the 18 - to 24 -year-old age group served as reference groups for these variables. Block 2 included cancer-related variables. The group of patients diagnosed at age $\geq 18$ years served as the reference group for age at diagnosis. Cancer diagnosis was recoded into the following three groups: CNS disease, hematologic malignancies (leukemias and lymphomas), and other solid tumor (which served as the reference group). Block 3 consisted of the depression rating. Block 4 included the health outcome variables (global health rating, number of medical conditions, number of hospital admissions, and cancer-related pain). Blocks were added in successive steps. At each step, improvement in model fit was evaluated using a likelihood ratio test. All tests were conducted at a $P=.05$ significance level.

\section{RESULTS}

A significantly larger proportion of survivors $(7.8 \%$; $95 \%$ CI, $7.3 \%$ to $8.4 \%$; 713 of 9,126 survivors) reported SI compared with controls ( $4.5 \%$; $95 \%$ CI, $3.9 \%$ to $5.4 \%$; 135 of 2,968 controls; $\mathrm{OR}=1.79 ; 95 \%$ $\mathrm{CI}, 1.4$ to 2.4). Table 2 shows the relationship of SI to cancer diagnosis and cancer treatment variables. Survivors of CNS cancers had the highest prevalence of SI (10.6\%) and were significantly more likely to report SI than the leukemia survivors ( $\mathrm{OR}=1.5 ; 95 \% \mathrm{CI}, 1.2$ to 1.9 ). SI was not associated with age at diagnosis, time since diagnosis, type of cancer therapy, recurrence, or second malignancy.

In the survivor cohort, ideation was not significantly associated with age or sex but was associated with low levels of educational attainment, lower household income, and lack of recent employment (Table 3). Among survivors with less than a 12th grade education, $14.0 \%$ reported SI compared with only $6.3 \%$ of survivors with a college or graduate education ( $\mathrm{OR}=2.4 ; 95 \% \mathrm{CI}, 1.9$ to 3.1 ). Marital status was associated with $\mathrm{SI}$, with both the never married $(\mathrm{OR}=1.5$; $95 \% \mathrm{CI}, 1.2$ to 1.8$)$ and previously married groups $(\mathrm{OR}=2.1 ; 95 \% \mathrm{CI}$, 1.7 to 2.8 ) more likely to report SI than the currently married survivors. In the siblings, the associations of SI with demographic variables followed a similar pattern, although many did not reach statistical significance (Table 3). Of note, age was associated with SI in the siblings, with older groups being less likely to report SI than the reference group (age 18 to 24 years). 


\begin{tabular}{|c|c|c|c|c|c|c|c|c|c|c|}
\hline \multirow[b]{3}{*}{ Variable } & \multirow[b]{3}{*}{ Total No. } & \multicolumn{4}{|c|}{ Survivors $(n=9,126)$} & \multicolumn{5}{|c|}{ Siblings $(n=2,968$ ) } \\
\hline & & \multicolumn{2}{|c|}{$\begin{array}{c}\text { Survivors With } \\
\text { SI }\end{array}$} & \multirow[b]{2}{*}{ OR } & \multirow[b]{2}{*}{$95 \% \mathrm{Cl}$} & \multirow[b]{2}{*}{ Total No. } & \multicolumn{2}{|c|}{$\begin{array}{l}\text { Siblings With } \\
\text { SI }\end{array}$} & \multirow[b]{2}{*}{ OR } & \multirow[b]{2}{*}{$95 \% \mathrm{Cl}$} \\
\hline & & No. & $\%$ & & & & No. & $\%$ & & \\
\hline Age at interview, years & 9,126 & & & & & 2,968 & & & & \\
\hline $18-24$ & 3,566 & 296 & 8.3 & 1.0 & Reference & 861 & 57 & 6.6 & 1.0 & Reference \\
\hline $25-29$ & 2,501 & 184 & 7.4 & 0.9 & 0.7 to 1.1 & 696 & 28 & 4.0 & $0.6^{*}$ & 0.4 to 0.9 \\
\hline $30-34$ & 1,859 & 143 & 7.7 & 0.9 & 0.7 to 1.1 & 647 & 22 & 3.4 & $0.5^{*}$ & 0.3 to 0.8 \\
\hline$\geq 35$ & 1,200 & 90 & 7.5 & 0.9 & 0.7 to 1.1 & 764 & 28 & 3.7 & $0.5^{*}$ & 0.3 to 0.9 \\
\hline Sex & 9,126 & & & & & 2,968 & & & & \\
\hline Male & 4,814 & 367 & 7.6 & 1.0 & Reference & 1,383 & 61 & 4.4 & 1.0 & Reference \\
\hline Female & 4,312 & 346 & 8.0 & 1.1 & 0.9 to 1.2 & 1,585 & 74 & 4.7 & 1.1 & 0.8 to 1.5 \\
\hline Education & 8,645 & & & & & 2,843 & & & & \\
\hline College/postgraduate & 2,766 & 175 & 6.3 & 1.0 & Reference & 1,128 & 42 & 3.7 & 1.0 & Reference \\
\hline High school + some college & 3,213 & 258 & 8.0 & $1.3^{*}$ & 1.0 to 1.6 & 1,041 & 52 & 5.0 & 1.2 & 0.8 to 1.8 \\
\hline Completed high school & 1,882 & 126 & 6.7 & 1.1 & 0.8 to 1.3 & 517 & 20 & 3.9 & 0.9 & 0.5 to 1.6 \\
\hline$<12$ years (some high school) & 784 & 110 & 14.0 & $2.4^{*}$ & 1.9 to 3.1 & 157 & 15 & 9.6 & $2.2^{*}$ & 1.2 to 4.2 \\
\hline Household income & 8,039 & & & & & 2,701 & & & & \\
\hline$\geq \$ 60,000$ & 2,026 & 110 & 5.4 & 1.0 & Reference & 1,020 & 36 & 3.5 & 1.0 & Reference \\
\hline$\$ 40,000-\$ 59,999$ & 1,787 & 122 & 6.8 & 1.3 & 1.0 to 1.7 & 666 & 33 & 5.0 & 1.4 & 0.9 to 2.2 \\
\hline$\$ 20,000-\$ 39,999$ & 2,440 & 187 & 7.7 & $1.4^{*}$ & 1.1 to 1.8 & 666 & 40 & 6.0 & $1.6^{*}$ & 1.0 to 2.6 \\
\hline$\$ 10,000-\$ 19,999$ & 1,080 & 105 & 9.7 & $1.9^{*}$ & 1.4 to 2.5 & 224 & 14 & 6.3 & 1.5 & 0.8 to 2.9 \\
\hline$<\$ 9,999$ & 706 & 118 & 16.7 & $3.5^{*}$ & 2.6 to 4.6 & 125 & 10 & 8.0 & 2.0 & 0.9 to 4.1 \\
\hline Worked in last year & 8,743 & & & & & 2,914 & & & & \\
\hline Yes & 7,838 & 571 & 7.3 & 1.0 & Reference & 2,713 & 122 & 4.5 & 1.0 & Reference \\
\hline No & 905 & 109 & 12.0 & $1.8^{*}$ & 1.4 to 2.2 & 201 & 11 & 5.5 & 1.3 & 0.7 to 2.4 \\
\hline Marital status & 8,909 & & & & & 2,914 & & & & \\
\hline Married & 3,758 & 222 & 5.9 & 1.0 & Reference & 1,665 & 47 & 2.8 & 1.0 & Reference \\
\hline Single/never married & 4,372 & 369 & 8.4 & $1.5^{*}$ & 1.2 to 1.8 & 971 & 62 & 6.4 & $2.0^{*}$ & 1.2 to 3.1 \\
\hline Formerly married & 779 & 92 & 11.8 & $2.1^{*}$ & 1.7 to 2.8 & 278 & 24 & 8.6 & $3.3^{*}$ & 2.0 to 5.6 \\
\hline
\end{tabular}

NOTE. Percentages are based on the total available data for each variable. ORs are adjusted for age and sex.

Abbreviations: SI, suicidal ideation; OR, odds ratio.

*OR differs significantly from 1.0.

Among survivors, indicators of poor health were consistently associated with higher prevalence of SI (Table 4). For example, survivors reporting poor health status had the highest prevalence of SI at $28.8 \%$, which is in sharp contrast to those reporting excellent health, of whom only $3.3 \%$ reported SI. Disabled status was associated with $\mathrm{SI}(\mathrm{OR}=2.7 ; 95 \% \mathrm{CI}, 2.2$ to 3.3), as were number and severity of medical conditions. Cancer-related pain was also significantly associated with SI in the survivor group. Only $5.8 \%$ of survivors with no cancer-related pain reported SI compared with $21.4 \%$ of those reporting the highest level of pain ( $\mathrm{OR}=4.5 ; 95 \% \mathrm{CI}, 3.3$ to 6.0$)$. In siblings, the relationships between $\mathrm{SI}$ and health status variables were similar, although the relationships with chronic conditions did not consistently reach statistical significance (Table 4). As expected, depression was strongly associated with SI in survivors $(\mathrm{OR}=20.4 ; 95 \%$ CI, 17.2 to 24.3 ) and siblings ( $\mathrm{OR}=28.0 ; 95 \% \mathrm{CI}, 19.0$ to 41.4 ). Of those reporting SI, $63.9 \%$ of survivors and $62.2 \%$ of siblings scored above the clinical cutoff on the depression measure.

Examining the health utilization information, only $20 \%$ of survivors reported a recent oncology visit, and there was no significant association with SI. Survivors reporting no routine physical examination within the last 5 years were somewhat more likely to report SI than those who reported a recent examination $(\mathrm{OR}=1.2 ; 95 \% \mathrm{CI}, 1.0$ to 1.5). SI was more prevalent among survivors reporting a greater number of recent hospital admissions, suggesting a psychological burden associated with medical morbidity. In siblings, the relationships between SI and recent physical examination and hospitalization variables were of similar magnitude but not statistically significant.

To test the hypothesis that SI in survivors is independently associated with physical health status after adjusting for demographic, disease, and depression variables, a hierarchical logistic regression analysis was performed (Table 5). Demographic variables entered in step 1 were not significantly associated with SI. The entry of disease and treatment variables at step 2 did significantly improve the fit of the model $(P<.01)$, as did the addition of the depression variable at step $3(P<.001)$. In the last step, the entry of the physical health variables added significantly to the model $(P<.001)$, indicating that even after the variance caused by demographic, cancer treatment, and depression variables was accounted for, physical health is significantly associated with SI. In the final model adjusting for all covariates, SI was significantly associated with a CNS cancer diagnosis, earlier ages of diagnosis, higher level of depression, poor health ratings, and cancer pain.

\section{DISCUSSION}

Adult survivors of childhood cancer were found to be significantly more likely to have SI than a group of noncancer controls. SI was 


\begin{tabular}{|c|c|c|c|c|c|c|c|c|c|c|}
\hline \multirow[b]{3}{*}{ Variable } & \multicolumn{5}{|c|}{ Survivors $(\mathrm{n}=9,126)$} & \multicolumn{5}{|c|}{ Siblings ( $n=2,968$ ) } \\
\hline & \multirow[b]{2}{*}{ Total No. } & \multicolumn{2}{|c|}{$\begin{array}{c}\text { Survivors With } \\
\text { SI }\end{array}$} & \multirow[b]{2}{*}{ OR } & \multirow[b]{2}{*}{$95 \% \mathrm{Cl}$} & \multirow[b]{2}{*}{ Total No. } & \multicolumn{2}{|c|}{$\begin{array}{c}\text { Siblings With } \\
\text { SI }\end{array}$} & \multirow[b]{2}{*}{ OR } & \multirow[b]{2}{*}{$95 \% \mathrm{Cl}$} \\
\hline & & No. & $\%$ & & & & No. & $\%$ & & \\
\hline Health status & 9,039 & & & & & 2,940 & & & & \\
\hline Excellent & 1,812 & 59 & 3.3 & 1.0 & Reference & 717 & 23 & 3.2 & 1.0 & Reference \\
\hline Very good & 3,457 & 182 & 5.3 & $1.7^{*}$ & 1.2 to 2.3 & 1,285 & 42 & 3.3 & 1.1 & 0.6 to 1.8 \\
\hline Good & 2,781 & 278 & 10.0 & $3.4^{*}$ & 2.5 to 4.5 & 785 & 48 & 6.1 & $2.0^{*}$ & 1.2 to 3.4 \\
\hline Fair & 843 & 146 & 17.3 & $6.4^{*}$ & 4.7 to 8.8 & 141 & 18 & 12.8 & $4.7^{*}$ & 2.4 to 9.0 \\
\hline Poor & 146 & 42 & 28.8 & $12.5^{*}$ & 8.0 to 19.5 & 12 & 2 & 16.7 & $6.7^{*}$ & 1.4 to 32.9 \\
\hline Disabled & 8,782 & & & & & 2,955 & & & & \\
\hline No & 7,916 & 535 & 6.8 & 1.0 & Reference & 2,906 & 127 & 4.4 & 1.0 & Reference \\
\hline Yes & 866 & 143 & 16.5 & $2.7^{*}$ & 2.2 to 3.3 & 49 & 8 & 16.3 & $4.7^{*}$ & 2.1 to 10.3 \\
\hline Chronic condition/grade & 9,126 & & & & & 2,968 & & & & \\
\hline None & 3,449 & 208 & 6.0 & 1.0 & Reference & 1,832 & 72 & 3.9 & 1.0 & Reference \\
\hline Grade 1 or 2 & 3,211 & 275 & 8.6 & $1.5^{*}$ & 1.2 to 1.8 & 958 & 53 & 5.5 & $1.6^{*}$ & 1.1 to 2.3 \\
\hline Grade 3 or 4 & 2,466 & 230 & 9.3 & $1.7^{*}$ & 1.4 to 2.0 & 178 & 10 & 5.6 & 1.7 & 0.9 to 3.4 \\
\hline No. of chronic conditions & 9,126 & & & & & 2,968 & & & & \\
\hline 0 & 3,449 & 208 & 6.0 & 1.0 & Reference & 1,832 & 72 & 3.9 & 1.0 & Reference \\
\hline 1 & 2,307 & 164 & 7.1 & 1.2 & 1.0 to 1.5 & 710 & 29 & 4.1 & 1.1 & 0.7 to 1.7 \\
\hline 2 & 1,272 & 92 & 7.2 & 1.3 & 1.0 to 1.6 & 249 & 18 & 7.2 & $2.2^{*}$ & 1.3 to 3.7 \\
\hline$\geq 3$ & 2,098 & 249 & 11.9 & $2.2^{*}$ & 1.8 to 2.7 & 177 & 16 & 9.0 & $3.1^{*}$ & 1.8 to 5.7 \\
\hline Pain medications & 8,556 & & & & & 2,896 & & & & \\
\hline No & 7,040 & 458 & 6.5 & 1.0 & Reference & 2,527 & 92 & 3.6 & 1.0 & Reference \\
\hline Yes & 1,516 & 205 & 13.5 & $2.3^{*}$ & 1.9 to 2.7 & 369 & 32 & 8.7 & $2.5^{*}$ & 1.6 to 3.8 \\
\hline Last physical examinations & 8,239 & & & & & 2,636 & & & & \\
\hline Within 2 years & 5,746 & 421 & 7.3 & 1.0 & Reference & 1,496 & 68 & 4.6 & 1.0 & Reference \\
\hline Within 3 to 4 years & 941 & 81 & 8.6 & 1.2 & 0.9 to 1.5 & 390 & 19 & 4.9 & 1.0 & 0.6 to 1.8 \\
\hline$\geq 5$ years/never & 1,552 & 136 & 8.8 & $1.2^{*}$ & 1.0 to 1.5 & 750 & 40 & 5.3 & 1.2 & 0.8 to 1.8 \\
\hline No. of hospital admissions & 8,970 & & & & & 2,950 & & & & \\
\hline 0 & 7,081 & 503 & 7.1 & 1.0 & Reference & 2,471 & 112 & 4.5 & 1.0 & Reference \\
\hline $1-5$ & 1,798 & 176 & 9.8 & $1.4^{*}$ & 1.2 to 1.7 & 472 & 20 & 4.2 & 0.9 & 0.6 to 1.5 \\
\hline$>5$ & 91 & 16 & 17.6 & $2.8^{*}$ & 1.6 to 4.8 & 7 & 1 & 14.3 & 3.2 & 0.4 to 27.2 \\
\hline Depression & 9,104 & & & & & 2,965 & & & & \\
\hline Low & 8,027 & 269 & 3.4 & 1.0 & Reference & 2,739 & 53 & 1.9 & 1.0 & Reference \\
\hline High & 1,077 & 443 & 41.1 & $20.4^{*}$ & 17.2 to 24.3 & 226 & 81 & 35.8 & $28.0^{*}$ & 19.0 to 41.4 \\
\hline Cancer pain & 8,762 & & & & & & & & & \\
\hline None & 6,899 & 403 & 5.8 & 1.0 & Reference & & & & & \\
\hline Small amount & 965 & 117 & 12.1 & $2.3^{*}$ & 1.8 to 2.8 & & & & & \\
\hline Medium amount & 599 & 86 & 14.4 & $2.7^{*}$ & 2.1 to 3.5 & & & & & \\
\hline Very bad, excruciating & 299 & 64 & 21.4 & $4.5^{*}$ & 3.3 to 6.0 & & & & & \\
\hline Visit oncology clinic & 9,103 & & & & & & & & & \\
\hline Yes & 1,749 & 136 & 7.8 & 1.0 & Reference & & & & & \\
\hline No & 7,354 & 576 & 7.8 & 1.0 & 0.8 to 1.2 & & & & & \\
\hline
\end{tabular}

strongly associated with survivors' physical health, even many years after the completion of therapy and when effects of cancer diagnosis, treatment, and depression had been taken into account. Although previous publications, based largely on case reports or small selected groups of survivors, have found survivors to report SI, ${ }^{15-17}$ the current study provides, to our knowledge, the first large-scale investigation of this topic. With the larger and more representative sample provided by CCSS, findings of increased SI can be more confidently accepted as reflecting a true difference between childhood cancer survivors and their same-age peers. The majority of survivors reported no SI, but the significant minority of those experiencing thoughts of ending their lives is a serious concern. SI, although only one aspect of a spectrum of suicidal symptoms, is important to understand because it is a significant risk factor for self-destructive behaviors and is itself an indicator of emotional suffering. ${ }^{25-27}$

By demonstrating that SI of survivors is associated with specific cancer diagnoses and health outcomes, the findings add to the understanding of the relationship between childhood cancer and risk for later SI. As hypothesized, poor physical health was associated with SI, even after adjusting for depression and other covariates. This is consistent with reports that pain and chronic medical conditions are a significant risk factor for suicide and SI. ${ }^{28-33}$ A previous CCSS study demonstrated that childhood cancer survivors are significantly more burdened by chronic medical conditions than controls, ${ }^{24}$ making any 


\begin{tabular}{|c|c|c|c|c|}
\hline Step & $\begin{array}{l}\text { Improvement } \\
\text { in Model Fit }\end{array}$ & $\begin{array}{c}\text { Final } \\
\text { B }\end{array}$ & Odds Ratio & $95 \% \mathrm{Cl}$ \\
\hline Step 1: Demographic & 2.50 & & & \\
\hline Female sex & & 0.17 & 1.2 & 1.0 to 1.4 \\
\hline \multicolumn{5}{|l|}{ Age, years } \\
\hline $25-29$ & & -0.05 & 1.0 & 0.8 to 1.2 \\
\hline $30-34$ & & -0.03 & 1.0 & 0.7 to 1.3 \\
\hline$\geq 35$ & & 0.13 & 1.1 & 0.8 to 1.6 \\
\hline \multicolumn{4}{|l|}{ Diagnosis } & \\
\hline Hematologic & & 0.04 & 1.0 & 0.8 to 1.3 \\
\hline CNS & & 0.38 & $1.5^{*}$ & 1.1 to 1.9 \\
\hline \multicolumn{5}{|l|}{ Age at diagnosis, years } \\
\hline$<3$ & & 0.62 & $1.9 \dagger$ & 1.2 to 3.0 \\
\hline $3-6$ & & 0.36 & 1.4 & 1.0 to 2.2 \\
\hline $7-10$ & & 0.52 & $1.7 \dagger$ & 1.1 to 2.5 \\
\hline $11-17$ & & 0.43 & $1.5+$ & 1.1 to 2.2 \\
\hline Step 3: Depression & $1180.52 \ddagger$ & & & \\
\hline Depression score $\geq 63$ & & 2.80 & $16.4 \ddagger$ & 13.7 to 19.7 \\
\hline $\begin{array}{l}\text { Step 4: Physical health } \\
\text { Health }\end{array}$ & \multicolumn{3}{|c|}{ Health } & \\
\hline Poor & & 0.97 & $2.6 \neq$ & 1.5 to 4.5 \\
\hline Fair & & 0.74 & $2.1 \neq$ & 1.5 to 3.0 \\
\hline Good & & 0.60 & $1.8 \ddagger$ & 1.3 to 2.5 \\
\hline Very good & & 0.22 & 1.2 & 0.9 to 1.7 \\
\hline \multicolumn{5}{|l|}{ No. of chronic conditions } \\
\hline 1 & & 0.05 & 1.1 & 0.8 to 1.3 \\
\hline 2 & & -0.18 & 0.8 & 0.6 to 1.1 \\
\hline$\geq 3$ & & -0.08 & 0.9 & 0.7 to 1.2 \\
\hline \multicolumn{5}{|l|}{ Cancer pain } \\
\hline Small amount & & 0.62 & $1.9 \neq$ & 1.4 to 2.4 \\
\hline Medium amount & & 0.54 & $1.7 \ddagger$ & 1.3 to 2.3 \\
\hline Very bad & & 0.71 & $2.0 \neq$ & 1.4 to 2.9 \\
\hline \multicolumn{5}{|l|}{ No. of hospital admissions } \\
\hline $1-5$ & & 0.04 & 1.0 & 0.8 to 1.3 \\
\hline$>5$ & & 0.30 & 1.3 & 0.7 to 2.6 \\
\hline $\begin{array}{l}{ }^{*} P<.01 \\
+P<.05 \\
\ddagger P<.001\end{array}$ & & & & \\
\hline
\end{tabular}

association with suicidal thoughts or other psychological symptoms critically important to understand in this population. Treatment of suicidal symptoms is often multifaceted, including crisis intervention and treatment for mental disorders (eg, substance abuse, depression) when present. ${ }^{34-36}$ Interventions for SI in cancer survivors may need to build on these models and broaden them to address physical health more directly. The relatively high utilization of hospital services among the suicidal survivors suggests that these points of contact with the health system could be used to address their emotional needs.

The increased risk for SI found among CNS tumor survivors was not anticipated but may be consistent with the known risks for neurocognitive late effects affecting education, employment, and social relationships in this population. ${ }^{13,37,38}$ Problems in these critical areas of personal development can lead to significant frustration and emotional distress, and these results suggest SI may be one manifestation of this. Significant associations of age and sex with suicidality are commonly reported in the literature, although the nature of these relationships depends on the specific suicidal symptoms under inves- tigation. $^{25,39}$ In the survivor sample, no relationship with SI was found, making the extent to which these variables play a role in the expression of suicidality in this population unclear. Future studies using longitudinal data and a broader array of suicidal symptoms may be useful in examining this more thoroughly. Finally, although SI is strongly associated with depression, the results are an important reminder that suicide risk may be present even when symptoms of depression are not.

A notable limitation of the study was use of a single item to assess recent SI. Suicidal symptoms can vary over short periods of time, making prevalence estimates from a single time point somewhat limited. In a previously reported study of 226 patients at a pediatric cancer survivor clinic (conducted by several members of the research team), SI was found in $12.8 \%$ of survivors, ${ }^{17}$ a rate that is considerably higher than the $7.8 \%$ in the CCSS cohort. However, in the survivor clinic study, multiple questions were used to assess SI. Only $8.8 \%$ of the clinic sample endorsed SI on the BSI-18 item alone, which is not substantially different from rate reported in the CCSS cohort. A more complete understanding of the nature of SI in this population will require detailed assessment of suicidal thoughts. Specifically, onset, duration, and intensity of suicidal thoughts as well as suicidal impulses, plans, or attempts will be critical to understanding more about the effect of SI on survivors' adaptation and functioning, as well as their risk for self-harm or suicide completion. Reliance on selfreported health outcomes is another limitation because reports of these conditions may be affected by emotional states in a manner that could potentially bias the results. A sibling control group could be a limitation, particularly if SI in siblings was less prevalent than in the general population, because this would tend to inflate the estimate of risk of SI in survivors. The SI rate for siblings that we found is similar or higher than other recent population estimates, ${ }^{25,40}$ making this type of bias somewhat unlikely.

Despite these limitations, study findings are consistent with the growing literature on suicidal thoughts and behaviors in cancer patients and survivors ${ }^{1-5,31,41,42}$ and have important implications for identifying and intervening with survivors most at risk. Medical variables, such as CNS cancer diagnosis, physical pain, and medical comorbidities, are typically available from medical records or patientcompleted forms and could be used to stratify survivors for targeted screening, particularly in situations where universal screening is not practical. Direct assessment of hopelessness and suicidal thoughts is recommended in evaluating cancer patients, ${ }^{43}$ and these results indicate that similar assessment should be routine for cancer survivors, especially those facing significant health problems or limitations in functioning. Depression screening is also important for identifying survivors with SI, but depression measures that do not specifically inquire about $\mathrm{SI}^{44,45}$ should not be expected to identify all survivors with SI. Research examining the aspects of depression (eg, anhedonia, sleep disturbance, and so on) most strongly associated with SI of survivors may be useful in enhancing depression screening for this group. Finally, the association of physical health with SI is an important reminder of the importance of a comprehensive biopsychosocial $^{46}$ perspective on survivorship care. Helping survivors find appropriate medical care for their treatment-related medical late effects is already a priority for improving the physical health of survivors $^{47}$ and may be essential to improving their emotional health as well. 


\section{AUTHORS' DISCLOSURES OF POTENTIAL CONFLICTS} OF INTEREST

The author(s) indicated no potential conflicts of interest.

\section{AUTHOR CONTRIBUTIONS}

Conception and design: Christopher J. Recklitis, Lisa R. Diller, Leslie L. Robison, Lonnie Zeltzer
Financial support: Christopher J. Recklitis, Lisa R. Diller, Leslie L. Robison Administrative support: Lisa R. Diller, Leslie L. Robison

Provision of study materials or patients: Leslie L. Robison Collection and assembly of data: Lisa R. Diller, Leslie L. Robison, Lonnie Zeltzer

Data analysis and interpretation: Christopher J. Recklitis, Lisa R. Diller, Xiaochun Li, Julie Najita, Leslie L. Robison, Lonnie Zeltzer

Manuscript writing: Christopher J. Recklitis, Lisa R. Diller, Xiaochun Li, Julie Najita, Leslie L. Robison, Lonnie Zeltzer

Final approval of manuscript: Christopher J. Recklitis, Lisa R. Diller, Xiaochun Li, Julie Najita, Leslie L. Robison

\section{REFERENCES}

1. Filiberti A, Ripamonti C: Suicide and suicidal thoughts in cancer patients. Tumori 88:193-199, 2002

2. Yousaf $U$, Christensen $M L$, Engholm G, et al: Suicides among Danish cancer patients 1971-1999. Br J Cancer 92:995-1000, 2005

3. Björkenstam C, Edberg A, Ayoubi S, et al: Are cancer patients at higher suicide risk than the general population? Scand J Public Health 33:208-214, 2005

4. Hem E, Loge JH, Haldorsen T, et al: Suicide risk in cancer patients from 1960 to 1999. J Clin Oncol 22:4209-4216, 2004

5. Llorente MD, Burke M, Gregory GR, et al: Prostate cancer: A significant risk factor for late-life suicide. Am J Geriatr Psychiatry 13:195-201, 2005

6. Gatta G, Capocaccia R, Stiller C, et al: Childhood cancer survival trends in Europe: A EUROCARE Working Group study. J Clin Oncol 23:3742-3751, 2005

7. Kenney LB, Laufer MR, Grant FD, et al: High risk of infertility and long term gonadal damage in males treated with high dose cyclophosphamide for sarcoma during childhood. Cancer 91:613-621, 2001

8. Adams MJ, Lipshultz SE: Pathophysiology of anthracycline- and radiation-associated cardiomyopathies: Implications for screening and prevention. Pediatr Blood Cancer 44:600-606, 2005

9. Hudson MM, Mertens $A C$, Yasui $Y$, et al: Health status of adult long-term survivors of childhood cancer: A report from the Childhood Cancer Survivor Study. JAMA 290:1583-1592, 2003

10. Dreyer ZE, Blatt J, Bleyer A: Late effects of childhood cancer and its treatment, in Pizzo PA Poplack DG (eds): Principles and Practice of Pediatric Oncology (ed 4). Philadelphia, PA, Lippincott Williams \& Wilkins, 2002, pp 1431-1461

11. Mertens AC, Liu Q, Neglia JP, et al: Causespecific late mortality among 5 -year survivors of childhood cancer: The childhood cancer survivor study. J Natl Cancer Inst 100:1368-1379, 2008

12. Barrera M, Shaw AK, Speechley KN, et al: Educational and social late effects of childhood cancer and related clinical, personal, and familial characteristics. Cancer 104:1751-1760, 2005

13. Mitby $P A$, Robison LL, Whitton JA, et al: Utilization of special education services and educational attainment among long-term survivors of childhood cancer: A report from the Childhood Cancer Survivor Study. Cancer 97:1115-1126, 2003

14. Waber DP, Carpentieri SC, Klar N, et al: Cognitive sequelae in children treated for acute lymphoblastic leukemia with dexamethasone or prednisone. J Pediatr Hematol Oncol 22:206-213, 2000
15. Kunin HM, Patenaude AF, Grier HE: Suicide risk in pediatric cancer patients: An exploratory study. Psychooncology 4:149-155, 1995

16. Recklitis C, O'Leary T, Diller L: Utility of routine psychological screening in the childhood cancer survivor clinic. J Clin Oncol 21:787-792, 2003

17. Recklitis CJ, Lockwood RA, Rothwell MA, et al: Suicidal ideation and attempts in adult survivors of childhood cancer. J Clin Oncol 24:3852-3857, 2006

18. Robison LL, Mertens AC, Boice JD: Study design and cohort characteristics of the Childhood Cancer Survivor Study: A multi-institutional collaborative project. Med Pediatr Oncol 38:229-239, 2002

19. Robison $L L$, Armstrong GT, Boice JD, et al: The Childhood Cancer Survivor Study: A National Cancer Institute-supported resource for outcome and intervention research. J Clin Oncol 27:23082318, 2009

20. St Jude Children's Research Hospital: The Childhood Cancer Survivor Study. http://www.stjude .org/ccss

21. Derogatis LR: BSI 18: Brief Symptom Inventory 18. Minneapolis, MN, National Computer Systems, 2000

22. Recklitis CJ, Parsons SK, Shih MC, et al: Factor structure of the Brief Symptom Inventory-18 in adult survivors of childhood cancer: Results from the Childhood Cancer Survivor Study. Psychol Assess 18:22-32, 2006

23. Derogatis $L R$, Morrow GR, Fetting J, et al: The prevalence of psychiatric disorders among cancer patients. JAMA 249:751-757, 1983

24. Oeffinger KC, Mertens AC, Sklar CA, et al: Chronic health conditions in adult survivors of childhood cancer. N Engl J Med 355:1572-1582, 2006

25. Kessler RC, Berglund P, Borges G, et al: Trends in suicide ideation, plans, gestures, and attempts in the United States, 1990-1992 to 2001. 2003. JAMA 293:2487-2495, 2005

26. Joiner TE Jr, Steer RA, Brown G, et al: Worstpoint suicidal plans: A dimension of suicidality predictive of past suicide attempts and eventual death by suicide. Behav Res Ther 41:1469-1480, 2003

27. Lewinsohn PM, Rohde P, Seeley JR: Psychosocial risk factors for future adolescent suicide attempts. J Consult Clin Psychol 62:297-305, 1994

28. Kurella M, Kimmel $P$, Young B, et al: Suicide in the United States end-stage renal disease program. J Am Soc Nephrol 16:774-781, 2005

29. Treharne GJ, Lyons AC, Kitas GD: Suicidal ideation in patients with rheumatoid arthritis: Research may help identify patients at high risk. BMJ 321:1290, 2000

30. Druss $B$, Pincus H: Suicidal ideation and suicide attempts in general medical illnesses. Arch Intern Med 160:1522-1526, 2000
31. Walker JL, Waters RA, Murray G, et al: Better off dead: Suicidal thoughts in cancer patients. J Clin Oncol 26:4725-4730, 2008

32. Ratcliffe G, Enns M, Belik S, et al: Chronic pain conditions and suicidal ideation and suicide attempts: An epidemiologic perspective. Clin J Pain 24:204-210, 2008

33. Tang N, Crane C: Suicidality in chronic pain: A review of the prevalence, risk factors and psychological links. Psychol Med 36:575-586, 2006

34. Comtois KA, Lineham MM: Psychosocial treatments of suicidal behaviors: A practice-friendly review. J Clin Psychol 62:161-170, 2006

35. Jacobs DG, Brewer ML: Application of the APA Practice Guidelines on Suicide to Clinical Practice. CNS Spectr 11:447-454, 2006

36. American Psychiatric Association: Practice Guidelines for the Treatment of Psychiatric Disorders Compendium. Arlington, VA, American Psychiatric Association, 2004

37. Pang JW, Friedman DL, Whitton JA, et al: Employment status among adult survivors in the Childhood Cancer Survivor Study. Pediatr Blood Cancer 50:104-110, 2008

38. Vannatta K, Gartstein MA, Short A, et al: A controlled study of peer relationships of children surviving brain tumors: Teacher, peer, and self ratings. J Pediatr Psychol 23:279-287, 1998

39. Centers for Disease Control and Prevention: Web-based Injury Statistics Query and Reporting System (WISOARS), Center for Injury Prevention and Control. http://www.cdc.gov/injury/wisqars/index.html

40. Cooper-Patrick L, Crum RM, Ford DE: Identifying suicidal ideation in general medical patients. JAMA 272:1757-1762, 1994

41. Misono S, Weiss NS, Fann JR, et al: Incidence of suicide in persons with cancer. J Clin Oncol 26:4731-4738, 2008

42. Miller M, Mogun $\mathrm{H}$, Azrael $\mathrm{D}$, et al: Cancer and the risk of suicide in older Americans. J Clin Oncol 26:4720-4724, 2008

43. Quill TE: Suicidal thoughts and actions in cancer patients: The time for exploration is now. J Clin Oncol 26:4705-4707, 2008

44. Zigmond AS, Snaith RP: The hospital anxiety and depression scale. Acta Psychiatr Scand 67:361 370,1983

45. Radloff L: The CES-D Scale: A self-report depression scale for research in the general population. Appl Psych Meas 1:385-401, 1977

46. Molina JA: Understanding the biopsychosocial model. Int J Psychiatry Med 13:29-36, 19831984

47. Institute of Medicine, National Research Council of the National Academies: From Cancer Patient to Cancer Survivor: Lost in Transition. Washington, DC, The National Academies Press, 2006 